\title{
The Air Quality and Detection of Streptococcus pneumoniae in the Pediatric Ward of Dr. Hasan Sadikin Hospital Bandung
}

\author{
Thiban Raj Manoraj, ${ }^{1}$ Yanti Mulyana, ${ }^{2}$ Sri Endah Rahayuningsih ${ }^{3}$ \\ ${ }^{1}$ Faculty of Medicine Universitas Padjadjaran, Indonesia, ${ }^{2}$ Department of Biomedical Sciences \\ Faculty of Medicine Universitas Padjadjaran, Indonesia, ${ }^{3}$ Department of Child Health Faculty of \\ Medicine Universitas Padjadjaran/Dr. Hasan Sadikin General Hospital Bandung, Indonesia
}

\section{Abstract}

Background: Nosocomial infection can be acquired by inhalation of droplets from contaminated air. In children, nosocomial pneumonia is mainly caused by Streptococcus pneumoniae. This study aimed to explore the air quality level and to detect Streptococcus pneumonia in the air of the Pediatric Ward of Dr. Hasan Sadikin Hospital, Bandung.

Methods: This was an observational descriptive study conducted in the Pediatric Ward of Dr. Hasan Sadikin Hospital in November 2012. The different number of modified tryptic soy agar (TSA) plates with $4 \%$ blood were exposed and placed in various rooms of the ward for 30 minutes between 12.00 $\mathrm{pm}$ to $1.00 \mathrm{pm}$ at heights between $1.0 \mathrm{~m}$ to $1.5 \mathrm{~m}$ and according to the respectively room air volume. After exposure, these plates were then incubated for 48 hours at $35^{\circ} \mathrm{C}$. The Colony Forming Units (CFU) on each plate was counted per Replicate Organism Detection and Counting (RODAC ${ }^{\mathrm{TM}}$ ). Detection of Streptococcus pneumonia was performed by detecting any round $\alpha$-hemolytic colonies on the TSA plate, confirmed by Gram staining, optochin susceptibility test, and the bile solubility test.

Result: The air quality in 13 rooms of the Pediatric Ward was generally poor ranging from 27.5 to 232.0 CFU/30 min, however, the concentration of microorganisms per cubic meter air was from 0.198 to $4.296 \mathrm{CFU} / \mathrm{m}^{3}$. Moreover, Streptococcus pneumoniae was not present in the air of the ward.

Conclusions: Although Streptococcus pneumoniae has not been detected, the air quality in the Pediatric Ward of Dr. Hasan Sadikin Hospital, Bandung is generally poor. General precautions need to be enhanced to increase the air quality in the hospital.

Keywords: Air quality, pediatric ward, Streptococcus pneumoniae

\section{Introduction}

The air quality has given its importance as public health concern since 1952, in time when there was a large increase in deaths during the severe air pollution episode in London, England. ${ }^{1}$ Indoor air quality (IAQ) is the nature of air inside a building that affects the health and well-being of its occupants. Prevention from infection of hospital workers and patients is accomplished by the control of IAQ. ${ }^{2}$ Especially in a pediatric ward, the air quality should be maintained at its best level since sick children have immature respiratory systems and low immune systems. The full maturation of lungs in human beings happens only 10 years after birth and not immediately after partus. ${ }^{3}$ Therefore, bad IAQ in the pediatric ward will make sick children vulnerable to any microorganisms in the air and may cause nosocomial infection.

Nosocomial infection is the infection occurring in patients during their stay in the hospital or another healthcare facility, to which the infection is not present or incubating at the time of admission. More than 1.4 million patients around the world suffer at any time with about 90,000 deaths per year due to nosocomial infection. Contamination and transmission through the air occur through droplets that can directly spread and be acquired by patients, or otherwise indirectly through medical device contamination. The air exchange rate, the number of activity carried out and the number of people in the ward

Correspondence: Thiban Raj Manoraj, Faculty of Medicine, Universitas Padjadjaran Jalan Raya Bandung-Sumedang KM 21, Jatinangor, Sumedang, Jawa Barat, Indonesia, Email: thiban_1990@yahoo.com 
determines the number of microorganisms in the air which indirectly determines the air quality. ${ }^{4}$

Nosocomial pneumonia mostly affects infants, young children and adults age 65 and above. The second most common nosocomial infection in the United States is pneumonia. Pneumonia accounts for $15 \%$ of all nosocomial infections and it is the second most common after urinary tract infection (UTI). The crude mortality rate and the attribute mortality rate of nosocomial pneumonia are $20 \%$ to $50 \%$ and $30 \%$ to $33 \%$ respectively. Sixty percent of all deaths attributed to nosocomial infections are due to pneumonia. ${ }^{5}$

Pneumonia specifically affects the lungs and it is a severe form of acute lower respiratory infection and it is the number one killer in children under 5 years old of age. Streptococcus pneumoniae is the most common cause of pneumonia among children in the world. ${ }^{6}$ In a vaccine trial data recently acquired, over $50 \%$ of pneumonia cases in Africa are caused by Streptococcus pneumoniae. ${ }^{6}$ In developing countries, over 150 million cases of pneumonia occur in children under five years old every year. Out of this large number, 2 million children will finally die and about 11 million to 20 million of them will need admission in healthcare facilities. ${ }^{6}$ The prevalence of childhood pneumonia in Indonesia is 6 million. ${ }^{7}$ Indonesia is also one of the 15 countries in which the childhood pneumonia cases account for three-quarters of childhood pneumonia worldwide. ${ }^{6}$ According to the Indonesian Health Profile 2007, there are 477,420 under-five children who have pneumonia and pneumonia causes deaths of $22.3 \%$ infants and $23.6 \%$ children under five years old. ${ }^{7}$ The incidence of pneumonia cases in children under five years old who receive treatment in Dr. Hasan Sadikin Hospital, Bandung in the years 2010 and 2011 are 259 and 394 respectively.

This study aimed to explore the air quality level in the Pediatric Ward of Dr. Hasan Sadikin Hospital, Bandung and whether Streptococcus pneumonia was present in the respectively ward.

\section{Methods}

This observational descriptive study was carried on in the Pediatric Ward of Dr. Hasan Sadikin Hospital, Bandung, in November 2012. The air samples were obtained by placing opened Petri dishes containing modified tryptic soy agar (TSA) with $4 \%$ blood plates in all rooms in the wards for 30 minutes at any time between $12.00 \mathrm{pm}$ and $1.00 \mathrm{pm}$. Each room was allocated with a different number of modified TSA with a $4 \%$ blood plates to collect air samples according to their respective air volumes. The designation was one modified TSA with $4 \%$ blood plate for $25 \mathrm{~m}^{3}$ air volume of the room. These plates were placed near doors, on tables and near patients' beds at any height between 1.0 to 1.5 meters above the floor level. After 30 minutes, these exposed plates were covered with their lids and placed in anaerobic cans before being incubated microaerophically ${ }^{8}$ for 48 hours at $35^{\circ} \mathrm{C}$.

The air quality was reported in mean CFU/30 minutes for each room. The number of perReplicate Organism Detection and Counting $\left(\right.$ RODAC $^{\mathrm{TM}}$ ) plate was then counted. According to RODAC ${ }^{\mathrm{TM}}$ 0-25 CFU was designated as good, 26-50 was fair and $>50$ was poor. ${ }^{9}$

The concentration of microorganisms per cubic meter of air $\left(\mathrm{CFU} / \mathrm{m}^{3}\right)$ was calculated by dividing the mean CFU value counted with the volumes of the respective rooms. This $\mathrm{CFU} / \mathrm{m}^{3}$ value for each room was then compared with the Hospital environmental health requirements by the Minister of Health of the Republic of Indonesia. The normal value was $<200 \mathrm{CFU} / \mathrm{m}^{3}$.

For the detection of Streptococcus pneumoniae, the colonies formed on the modified TSA with $4 \%$ blood plates were viewed thoroughly for any round $\alpha$-hemolytic colonies. ${ }^{10}$ If there was a presence of such colony, then Gram staining was performed in which positive for the presence of Streptococcus pneumoniae would give dark blue color upon staining. Then, optochin susceptibility test was performed to check for any zone of inhibition. A zone of inhibition of $\geq 14 \mathrm{~mm}$ indicated a positive test. Another test was also performed; the bile solubility test which would give a positive result for Streptococcus pneumoniae. ${ }^{11,12}$ When there was no round $\alpha$-hemolytic colony was found, it was reported as negative for the detection of Streptococcus pneumoniae, and the other three tests were not carried out.

\section{Results}

In total, there were thirteen rooms the Pediatric Ward of Dr. Hasan Sadikin Hospital, Bandung, and the CFU per 30 minutes formed on each agar plate is placed in those rooms were depicted in Table 1. The mean of CFU/30 minutes which determined the air quality level was compared to the criteria of contamination 
Table 1 The Colony Forming Unit per 30 Minutes Formed on Each Agar Plate Placed in 13 Rooms in the Pediatric Ward of Dr. Hasan Sadikin Hospital, Bandung

\begin{tabular}{|c|c|c|c|c|c|c|c|}
\hline \multirow{2}{*}{ Room no } & \multicolumn{6}{|c|}{$\mathrm{CFU} / 30 \mathrm{~min}$} & \multirow{2}{*}{ Mean } \\
\hline & A & B & $\mathrm{C}$ & $\mathrm{D}$ & $\mathrm{E}$ & $\mathrm{F}$ & \\
\hline 1 & 26 & 32 & 27 & 22 & 34 & 24 & 27.5 \\
\hline 2 & 34 & 27 & 36 & 41 & 19 & 22 & 29.8 \\
\hline 3 & 92 & 83 & 108 & 77 & 92 & 78 & 88.3 \\
\hline 4 & 115 & 119 & 122 & 146 & 152 & 120 & 129.0 \\
\hline 5 & 133 & 153 & 106 & 125 & 172 & 98 & 131.2 \\
\hline 6 & 190 & 156 & 244 & 180 & 246 & 145 & 193.5 \\
\hline 7 & 79 & 96 & 74 & 90 & - & - & 84.8 \\
\hline 8 & 154 & 152 & 163 & 165 & - & - & 158.5 \\
\hline 9 & 119 & 176 & 153 & 114 & - & - & 140.5 \\
\hline 10 & 194 & 234 & 268 & - & - & - & 232.0 \\
\hline 11 & 132 & 97 & 117 & - & - & - & 115.3 \\
\hline 12 & 83 & 74 & 66 & - & - & - & 74.3 \\
\hline 13 & 49 & 64 & - & - & - & - & 56.5 \\
\hline
\end{tabular}

Note: CFU/30 minutes; Colony Forming Unit per 30 minutes

by RODAC ${ }^{\mathrm{TM}}$ for each room.

Interestingly, round $\alpha$-hemolytic colonies were not observed in TSA plates, suggesting that Streptococcus pneumoniae was not present in the air of all rooms in the Pediatric Ward of Dr. Hasan Sadikin Hospital.

According to RODAC ${ }^{\mathrm{TM}}$ contamination criteria classification, no single room in the Pediatric Ward of Dr. Hasan Sadikin Hospital, Bandung was recorded as good for their air quality; the air quality in Rooms 1 and 2 was fair, whereas, the air quality in Rooms 3 to 13 were poor. However, based on the air quality guidelines published by the Hospital environmental health requirements by the Minister of Health of the Republic of Indonesia, all the 13 rooms had less than $200 \mathrm{CFU} / \mathrm{m}^{3}$ of microorganisms ranging from $0.198 \mathrm{CFU} /$ $\mathrm{m} 3$ to $4.296 \mathrm{CFU} / \mathrm{m}^{3}$, thus these rooms had acceptable environmental health.

\section{Discussion}

This study has shown that Streptococcus pneumoniae was not detected in the air of all rooms in the Pediatric Ward of Dr. Hasan Sadikin Hospital, Bandung, suggesting that there is thus no transmission of Streptococcus pneumoniae from patients or any other occupants of the ward through droplets. Therefore, pediatrics or children who are admitted to the Pediatric Ward of Dr. Hasan
Sadikin Hospital, Bandung is safe enough from acquiring nosocomial pneumonia caused by Streptococcus pneumoniae.

Interestingly, the air quality in Rooms 1 and 2 are generally better than the other 11 rooms in the Pediatric Ward of Dr. Hasan Sadikin Hospital, Bandung. This is because Rooms 1 and 2 are neonatology wards. Since neonates are newborns and their immune systems are still weak and not developed yet to combat pathogens, Rooms 1 and 2 are kept as clean as possible. Anybody including healthcare personnel entering Rooms 1 and 2 must wash their hands first at the water pipes prepared outside; they must also remove whatever footwear they are wearing. The instructions to wash hands and to remove footwears are clearly stated on the doors of Rooms 1 and 2. Washing hands and removing footwears before entering those rooms reduce the likelihood of microorganisms from entering the rooms. Microorganisms are significantly reduced by soaps used to wash hands before they enter. Beside, only these two rooms are air-conditioned. Since, the air-conditioned Rooms 1 and 2 have better air qualities compared to the other rooms in the ward, it suggests that air conditioning may play a major role in maintaining the air quality inside buildings, because air conditioning units have the capability of circulating air from inside buildings to the outside and vice 
Table 2 Concentration of Microorganisms Per Cubic Meter of Air(CFU/m3) in the Rooms of Pediatric Ward in Dr. Hasan Sadikin Hospital, Bandung

\begin{tabular}{cc}
\hline Room & $\begin{array}{c}\text { The concentration of microorganisms per cubic meter of air } \\
\text { (CFU/m3) }\end{array}$ \\
\hline 1 & $0.198^{*}$ \\
2 & $0.215^{*}$ \\
3 & $0.636^{* *}$ \\
4 & $0.930^{* *}$ \\
5 & $0.946^{* *}$ \\
6 & $1.395^{* *}$ \\
7 & $1.019^{* *}$ \\
8 & $1.904^{* *}$ \\
9 & $1.688^{* *}$ \\
10 & $4.296^{* *}$ \\
11 & $2.135^{* *}$ \\
12 & $1.376^{* *}$ \\
13 & $1.404^{* *}$ \\
\hline
\end{tabular}

Note: RODACTM contamination criteria classification; the air quality was fair* or poor **. The CFU/m3 value for each room was compared with the Hospital environmental health requirementsby Minister of Health of the Republic of Indonesia. The normal value was $<200 \mathrm{CFU} / \mathrm{m} 3$.

versa. This ensures that the air inside the pediatric ward to be all the time changing; removing microorganisms from indoor to outdoor. Air conditioning units also can clean the air via filters fitted in them. These filters are responsible for filtering dust and microparticles and help in maintaining good air quality.

Interestingly, Room 10 where is recorded to be the highest value for the concentration of microorganisms per cubic meter of air $\left(4.296 \mathrm{CFU} / \mathrm{m}^{3}\right)$ is a Gastroenterology ward with 8 persons including 3 patients during the time of observation. This room is one of the smallest rooms in the Pediatric Ward, where there is a possibility for the concentration of microorganisms in the air to be very high, leading to the worst air quality. These microorganisms mainly come from the skin and the respiratory system of the people. Aside from that, Room 10 also has only one door and the windows are all not opened. This leads to poor air ventilation as air takes a long time to circulate in and out of the room. There is no constant changing of the indoor air leading to an accumulation of microorganisms to increase due time. Most importantly, Room 10 also has a toilet. Since a toilet is considered to be dirty, and microorganisms accumulate there constantly, it can be a cause for the increase of microorganisms in Room 10. The source of these microorganisms in the toilet can be from the excretions of people like the urine and feces or even from the phlegm or sputum. These microorganisms from the toilet are then brought out to Room 10 by people who use the toilet.

According to the criteria of contamination by RODAC ${ }^{\mathrm{TM}}$, the air quality in the Pediatric Ward of Dr. Hasan Sadikin Hospital, Bandung is poor. It may be caused by the air ventilation in the ward which is generally bad. Although there are many windows and doors in the ward, they are almost closed all the time. This makes the condition inside the ward to be stuffy as there is a very limited circulation of air. When there is limited circulation of the air, there is no changing of indoor air as stated above. Indoor air is limitedly exchanged with fresh outdoor air. This leads to an accumulation of microorganisms in the indoor air of the rooms in the pediatric ward which are suspended in the air.

The Pediatric Ward is almost always crowded with people. Doctors, nurses, medical interns, trainee nurses, attendants, cleaners, nutritionists, parents, family members, and other companions are always in the ward. Microorganisms can be brought by this crowd into the ward. These microorganisms are mainly transmitted from the skin and the respiratory tract of these people in the form 
of droplets or bioaerosol. Therefore, a big crowd can influence the indoor air quality as microorganisms in the form of droplets or bioaerosol will be accumulated by this large number of people in the air of the ward.

This study has limitations, that this study is a single time of observation. More time frame periods might give useful data. As a positive control situation, the room occupied with pneumonia patients might be examined for the presence of Streptococcus pneumoniae.

To conclude, although Streptococcus pneumoniae is not detected, the air quality in the Pediatric Ward of Dr. Hasan Sadikin Hospital, Bandung is generally poor. The healthcare workers like doctors, nurses, medical interns, and trainee nurses may wear hand gloves and mask to cover their mouths and nose. Furthermore, they need to wash their hands accordingly. The air ventilation system needs to be refreshed and the general precautions need to be enhanced to increase the air quality in the hospital.

\section{References}

1. Hasselback P, Taylor E. Air quality health index variation across British Columbia. Interior Health. 2010 [cited 2013 January 29]. Available from: https://www2.gov. bc.ca/assets/gov/environment/air-landwater/air/reports-pub/aqhi-variation-bc. pdf

2. Leung $M$, Chan AH. Control and management of hospital indoor air quality. Med Sci Monit. 2006;12(3):SR17-23.

3. Sadler TW.Langman's Medical Embryology. $11^{\text {th }}$ ed. Philadelphia: Lippincott Williams \& Wilkins; 2009. p. 206.

4. Ducel G, Fabry J, Nicolle L. Prevention of hospital acquired infections: a practical guide. Med J Armed Forces India. 2004;60(3):312.
5. Tablan OC, Anderson LJ, Besser R, Bridges C, Hajjeh R, et al. Guidelines for preventing healthcare-associated pneumonia, 2003: recommendations of CDC and the Healthcare Infection Control Practices Advisory Committee. MMWR Recomm Rep. 2004;53(RR-3):1-36.

6. Wardlaw T, Johansson EW, Hodge M. Pneumonia:the forgotten killer of children. Geneva: UNICEF/WHO; 2006.

7. Departemen Kesehatan Republik Indonesia. Profil Kesehatan Indonesia 2007. Jakarta:Departemen Kesehatan Republik Indonesia; 2008.

8. Brooks GF, Carroll KC, Butel JS, Morse SA. Jawetz, Melnick \& Adelberg's Medical Microbiology. $24^{\text {th }}$ ed. McGraw-Hill Companies; 2007. p. 241-243

9. Becton, Dickinson and Company. BBLTM Prepared RODAC ${ }^{\mathrm{TM}}$ Plates. Spark, MD, USA: Becton, Dickinson and Company; 2005. [downloaded on 22 March 2012] Available at: http:// legacy.bd.com/ds/technicalCenter/ inserts/8835631JAA(0205).pdf.

10. Shimeld LA, Rodgers AT. Essentials of diagnostic microbiology. Clifton Park, United States: Delmar Cengage Learning; 1999. p 117-130.

11. Kaijalainen T. The identification of Streptococcus pneumoniae. Volumes 11. Oulu, Finland: National Public Health Institute; 2006. p. 32.

12. Perilla MJ, Ajello G, Bopp C, Elliot J, Facklam R, Knapp JS, et al. Manual for the laboratory identification and antimicrobial susceptibility testing for bacterial pathogens of public health importance in the developing world: Haemophilus influenzae, Neisseria meningitidis, Streptococcus pneumoniae, Neisseria gonorrhoea, Salmonella typhi, Shigella, and Vibrio cholerae. Geneva: CDS Information Resource Center, WHO; 2003. 